\title{
Gas-Phase Ion/Ion Reactions of Transition Metal Complex Cations with Multiply Charged Oligodeoxynucleotide Anions
}

\author{
Christopher K. Barlow, ${ }^{\mathrm{a}, \mathrm{b}, \mathrm{c}}$ Brittany D. M. Hodges, ${ }^{\mathrm{d}} \mathrm{Yu} \mathrm{Xia}^{\mathrm{d}}{ }^{\mathrm{d}}$ \\ Richard A. J. O'Hair, ${ }^{a, b, c}$ and Scott A. McLuckey ${ }^{d}$ \\ a School of Chemistry, University of Melbourne, Melbourne, Australia \\ ${ }^{\mathrm{b}}$ Bio 21 Institute, University of Melbourne, Melbourne, Australia \\ c ARC Centre of Excellence in Free Radical Chemistry and Biotechnology, Melbourne, Australia \\ d Department of Chemistry, Purdue University, West Lafayette, Indiana, USA
}

Multiply deprotonated hexadeoxyadenylate anions, $\left(\mathrm{A}_{6}-\mathrm{nH}\right)^{\mathrm{n}-}$, where $n=3-5$, have been subjected to reaction with a range of divalent transition-metal complex cations in the gas phase. The cations studied included the bis- and tris-1,10-phenanthroline complexes of $\mathrm{Cu}^{\mathrm{II}}$, $\mathrm{Fe}^{\mathrm{II}}$, and $\mathrm{CO}^{\mathrm{II}}$, as well as the tris-1,10-phenanthroline complex of $\mathrm{Ru}^{\mathrm{II}}$. In addition, the hexadeoxyadenylate anions were subjected to reaction with the singly charged $\mathrm{Fe}^{\mathrm{III}}$ and $\mathrm{Co}^{\mathrm{III}}$ $\mathrm{N}, \mathrm{N}^{\prime}$-ethylenebis(salicylideneiminato) complexes. The major competing reaction channels are electron-transfer from the oligodeoxynucleotide anion to the cation, the formation of a complex between the anion and cation, and the incorporation of the transition-metal into the oligodeoxynucleotide. The latter process proceeds via the anion/cation complex and involves displacement of the ligand(s) in the transition-metal complex by the oligodeoxynucleotide. Competition between the various reaction channels is governed by the identity of the transition-metal cation, the coordination environment of the metal complex, and the oligodeoxynucleotide charge state. In the case of the divalent metal phenanthroline complexes, competition between electron-transfer and metal ion incorporation is particularly sensitive to the coordination number of the reagent metal complexes. Both electron-transfer and metal ion incorporation occur to significant extents with the bis-phenanthroline ions, whereas the trisphenanthroline ions react predominantly by metal ion incorporation. To our knowledge this work reports the first observations of the gas-phase incorporation of multivalent transition-metal cations into oligodeoxynucleotide anions and represents a means for the selective incorporation of transition-metal counter-ions into gaseous oligodeoxynucleotides. (J Am Soc Mass Spectrom 2008, 19, 281-293) @ 2008 American Society for Mass Spectrometry

$\mathrm{T}$ The development of gentle ionization methods such as matrix-assisted laser desorption ionization (MALDI) [1-5] and electrospray (ESI) [6-8] have allowed the formation of gas-phase ions of biopolymers, including oligodeoxynucleotides (ODNs), making these ions amenable to study by mass spectrometry. Like peptides and proteins, ODNs are amphoteric, [9] allowing formation of either positively or negatively charged ions. Formation of negatively charged oligonucleotides is quite facile using ESI and, as a result, negatively charged ODN ions have been the most widely studied [9]. Oligodeoxynucleotide ions with bound metals formed by MALDI or ESI, especially those containing transition metals, have shown fragmentation behavior, which is distinct and complementary to that of ions devoid of metals [6-8].

Address reprint requests to Dr. S. A. McLuckey, Department of Chemistry, Purdue University, West Lafayette, IN 47907-2084, USA. E-mail: mcluckey@ purdue.edu
The study of the interaction of transition metals with DNA is of critical importance, given the variety of roles such interactions fulfill. Transition-metal complexes display nuclease activity and consequently complexes such as (methidium-propyl-EDTA)iron(II) have been utilized as footprinting agents [10]. Ruthenium(II) complexes have been extensively examined as spectroscopic probes of local DNA structure [11, 12]. The mechanism of action of the chemotherapeutic agent cisplatin involves binding to DNA to prevent replication [13-15]. Mass spectrometry has been used as a tool for the examination of ODN complexes with metal ions [16]. To date, in mass spectrometric studies, metal ion incorporation into the ODN occurs before, or in conjunction with, the ionization step, typically through the addition of metal salts to the sample matrix. This approach has the disadvantage of leading to a mixture of ions with different numbers of metal ion adducts, and in the case of ESI, different charge states.

Ion/ion reactions have been used to study the primary structure of biopolymers through processes such 
as electron-transfer dissociation (ETD), to manipulate charge states, and to form novel ion types which may not be available directly from ESI [17, 18]. Ion/ion reactions can be generally categorized into three types: charge-transfer (including proton and electron-transfer), complex formation, and metal cation exchange. Careful choice of reagents for ion/ion reactions can provide some control over the extent to which each of these reaction pathways contributes to the ion/ion reaction products observed $[19,20]$. Factors that play important roles in determining the relative contributions of these reaction pathways are the reactant identities, the charges of the reactant ions, and the reaction exothermicity.

Metal cation exchange is a type of ion/ion reaction that may be used to synthesize new species in the gas phase. Such reactions have largely been used to substitute metal ions for protons in peptide ions. For example, metal containing anions of the form MetalX $\mathrm{X}_{2-}$ where Metal is a singly charged alkali or transition-metal and $\mathrm{X}$ is a common counter ion such as a halide, acetate, or nitrate have been used as reagents [21-24]. Gas-phase metal containing peptide ions formed in this way have exhibited dissociation behavior identical to those formed in solution by mixing the metal salt with the peptide. The advantage of forming metal containing biopolymer ions via the ion/ion reaction approach is that it provides greater control over the selection of the reactant species and allows for independent optimization of ionization conditions for the analyte ion and the reagent ion.

Cationic metal complexes provide an opportunity for the gas-phase synthesis of new transition-metal-ODN complex ions via metal cation exchange reactions. These novel transition-metal-ODN ions can also provide a method to study the various factors influencing the relative contributions of electron-transfer, proton transfer, complex formation, and cation exchange in gasphase ion/ion reactions with ODN anions. In addition, these transition-metal containing ions may provide new and complementary fragmentation information when subjected to collision induced dissociation (CID) or other dissociation techniques. Previous studies have shown that ESI can be used to readily form gaseous complex ions composed of a transition-metal and one or more multi-dentate ligands [25-28]. Such metal complex ions have been the subject of extensive study including CID [29-33] and ion/molecule reactions [3436]. These studies have clearly shown the importance of coordination geometry and ligand identity on the reactivities of these ions and are consistent with the much larger body of work devoted to the chemistry of gaseous transition-metal ions [37-43]. They strongly suggest that a degree of control over ion/ion reactivity might be afforded by selection of metal, metal oxidation state, ligand, and ligand number.

Here, multiply charged hexadeoxyadenylate (hexa-dA) anions, $\left(\mathrm{A}_{6}-\mathrm{nH}\right)^{\mathrm{n}-}$, where $n=3-5$, have been used as models for ODN anions in a study of the ion/ion reaction behavior of multiply charged anions with multiply charged divalent transition-metal multi-dentate ligand complex cations. The ion/ion reaction behavior of latefirst row divalent transition metals $\mathrm{Cu}(\mathrm{II}), \mathrm{Co}(\mathrm{II})$, and $\mathrm{Fe}(\mathrm{II})$ in complexes with 1,10-phenanthroline (denoted herein as "phen") is emphasized. Results obtained with complexes of trivalent cobalt or iron and $N, N^{\prime}$-ethylenebis(salicylideneiminato) (denoted herein as "salen") complexes as well as those for $\left[\mathrm{Ru}^{\mathrm{II}}(\mathrm{phen})_{3}\right]^{2+}$ are also presented to illustrate the range of ion/ion reaction phenomenology observed.

\section{Experimental}

\section{Mass Spectrometry}

Nanospray emitters were pulled from borosilicate capillaries (1.55 mm o.d., $0.86 \mathrm{~mm}$ i.d.) using a P-87 Flaming/Brown micropipet puller (Sutter Instruments, Novato, CA). The electrospray solutions were loaded into these nanospray emitter tips, and a wire was inserted into the tip to make electrical contact with the analyte solution. For hexa-dA, a stainless steel wire was used, while a platinum wire was used for metal complex solutions.

Ionization was performed using a home-built pulsed dual nanoelectrospray ionization (nano-ESI) source that has been described previously [44]. Briefly, this pulsed dual source was comprised of two nano-ESI emitters, which were pulsed alternately on or off in each scan by the software. High voltages applied to the nano-ESI emitters were optimized separately and were independently generated by two high-voltage power supplies from the instrument and a fast high voltage pulser (GRX-1.5K-E; Directed Energy Inc., Fort Collins, CO). Ions of either polarity could be independently optimized and directed into the mass spectrometer using this method.

All experiments were performed with a quadrupole/ time-of-flight tandem mass spectrometer (QSTAR XL; Applied Biosystems/MDS SCIEX, Concord, ON, Canada) that has been modified for ion/ion reactions [45]. Molecular nitrogen was used as the collision gas. The instrument was controlled by Daetalyst software, a research version of software developed by MDS SCIEX, which provided full control for initiating each ion source and for applying the appropriate potentials and their timing to the ion path.

In a typical experiment, hexa-dA anions were produced via the negative nano-ESI source and the ions of interest were isolated as they passed through Q1. The isolated anions were subsequently directed into the Q2 linear ion trap (LIT) $(50 \mathrm{~ms})$, where they were trapped. Reagent cations of interest were then similarly generated in the gas phase by positive nano-ESI of the corresponding metal solution, and similarly the reagent ion of interest was selected isolated in Q1, and introduced into the Q2 LIT (30-100 ms), where ions of both polarities were allowed to react in the LIT over a variable reaction period (20-200 ms). Note that due to significant variations in numbers of ions from one 
Table 1. Normalized abundances of the primary product ions from ion/ion reactions for the $\left[\mathrm{Cu}^{\mathrm{II}}(\mathrm{phen})_{\mathrm{x}}\right]^{2+},\left[\mathrm{Co}{ }^{\mathrm{II}}(\mathrm{phen})_{\mathrm{x}}\right]^{2+}$, $\left[\mathrm{Fe}^{\mathrm{II}}(\mathrm{phen})_{\mathrm{x}}\right]^{2+}$ complexes. The electron transfer relative abundance also includes the signal from the oxygen adduct noted in the text as well as signals due to fragmentation

\begin{tabular}{lcc}
\hline \multicolumn{1}{c}{ Reactants } & Reaction 1 (electron transfer) & Reaction 2 (metal transfer) \\
\hline \hline$\left[\mathrm{Cu}(\text { phen })_{2}\right]^{2+}+\left(\mathrm{A}_{6}-3 \mathrm{H}\right)^{3-}$ & $0.71 \pm 0.05$ & $0.29 \pm 0.05$ \\
{$\left[\mathrm{Co}(\text { phen })_{2}\right]^{2+}+\left(\mathrm{A}_{6}-3 \mathrm{H}\right)^{3-}$} & $0.43 \pm 0.03$ & $0.57 \pm 0.03$ \\
{$\left[\mathrm{Fe}(\text { phen })_{2}\right]^{2+}+\left(\mathrm{A}_{6}-3 \mathrm{H}\right)^{3-}$} & $0.39 \pm 0.07$ & $0.61 \pm 0.07$ \\
{$\left[\mathrm{Cu}(\text { phen })_{3}\right]^{2+}+\left(\mathrm{A}_{6}-3 \mathrm{H}\right)^{3-}$} & $0.16 \pm 0.03$ & $0.84 \pm 0.03$ \\
{$\left[\mathrm{Co}(\text { phen })_{3}\right]^{2+}+\left(\mathrm{A}_{6}-3 \mathrm{H}\right)^{3-}$} & $0.04 \pm 0.01$ & $0.96 \pm 0.01$ \\
{$\left[\mathrm{Fe}(\text { phen })_{3}\right]^{2+}+\left(\mathrm{A}_{6}-3 \mathrm{H}\right)^{3-}$} & $0.02 \pm 0.006$ & $0.98 \pm 0.006$ \\
{$\left[\mathrm{Cu}(\text { phen })_{2}\right]^{2+}+\left(\mathrm{A}_{6}-4 \mathrm{H}\right)^{4-}$} & $0.52 \pm 0.07$ & $0.48 \pm 0.07$ \\
{$\left[\mathrm{Co}(\text { phen })_{2}\right]^{2+}+\left(\mathrm{A}_{6}-4 \mathrm{H}\right)^{4-}$} & $0.35 \pm 0.05$ & $0.65 \pm 0.05$ \\
{$\left[\mathrm{Fe}(\text { phen })_{2}\right]^{2+}+\left(\mathrm{A}_{6}-4 \mathrm{H}\right)^{4-}$} & $0.25 \pm 0.05$ & $0.75 \pm 0.05$ \\
{$\left[\mathrm{Cu}(\text { phen })_{3}\right]^{2+}+\left(\mathrm{A}_{6}-4 \mathrm{H}\right)^{4-}$} & $0.15 \pm 0.04$ & $0.85 \pm 0.04$ \\
{$\left[\mathrm{Co}(\text { phen })_{3}\right]^{2+}+\left(\mathrm{A}_{6}-4 \mathrm{H}\right)^{4-}$} & $0.10 \pm 0.01$ & $0.90 \pm 0.01$ \\
{$\left[\mathrm{Fe}(\text { phen })_{3}\right]^{2+}+\left(\mathrm{A}_{6}-4 \mathrm{H}\right)^{4-}$} & $0.06 \pm 0.02$ & $0.94 \pm 0.02$ \\
{$\left[\mathrm{Cu}(\text { phen })_{2}\right]^{2+}+\left(\mathrm{A}_{6}-5 \mathrm{H}\right)^{5-}$} & $0.71 \pm 0.05$ & $0.29 \pm 0.05$ \\
{$\left[\mathrm{Co}(\text { phen })_{2}\right]^{2+}+\left(\mathrm{A}_{6}-5 \mathrm{H}\right)^{5-}$} & $0.65 \pm 0.03$ & $0.35 \pm 0.03$ \\
{$\left[\mathrm{Fe}(\text { phen })_{2}\right]^{2+}+\left(\mathrm{A}_{6}-5 \mathrm{H}\right)^{5-}$} & $0.69 \pm 0.07$ & $0.31 \pm 0.07$ \\
{$\left[\mathrm{Cu}(\text { phen })_{3}\right]^{2+}+\left(\mathrm{A}_{6}-5 \mathrm{H}\right)^{5-}$} & $0.36 \pm 0.05$ & $0.64 \pm 0.05$ \\
{$\left[\mathrm{Co}(\text { phen })_{3}\right]^{2+}+\left(\mathrm{A}_{6}-5 \mathrm{H}\right)^{5-}$} & $0.42 \pm 0.04$ & $0.58 \pm 0.04$ \\
{$\left[\mathrm{Fe}(\text { phen })_{3}\right]^{2+}+\left(\mathrm{A}_{6}-5 \mathrm{H}\right)^{5-}$} & $0.42 \pm 0.04$ & $0.58 \pm 0.04$ \\
\hline
\end{tabular}

The data for each combination of metal complex and (hexa-dA) charge state are the average of three or more experiments, shown with the standard deviations of the results. Data were corrected for electron emission from pre-ion/ion data that showed emission rates about 10 times lower than the ion/molecule proton transfer rate for $\left(\mathrm{A}_{6}-5 \mathrm{H}\right)^{5-}$, and an emission rate about 100 times lower for both $\left(\mathrm{A}_{6}-4 \mathrm{H}\right)^{4-}$ and $\left(\mathrm{A}_{6}-3 \mathrm{H}\right)^{3-}$.

experiment to the next, the overall ion/ion reaction rates were variable. Reaction times were varied to maintain comparable extents of reaction. In particular, reaction times were varied to yield good signal-to-noise ratios for the first generation ion/ion reaction products while minimizing the appearance of products from sequential ion/ion reactions. Ion/ion reaction products were finally mass analyzed by a reflectron time-of-flight (TOF) analyzer (20-50 ms). The spectra shown in this study were typically an average of 50-200 scans. Data shown were normalized to the most abundant product ion. The reaction time (the time in which both positive and negative ions are present in the trap) consisted of two parts: the cation injection time and the subsequent mutual storage time. The data listed in Table 1 are the averages of at least three experiments, and these results are reported with the standard deviations of these experimental results.

In some cases, post ion/ion reaction spectra following reactions of the $\left(\mathrm{A}_{6}-3 \mathrm{H}\right)^{3-}$ and $\left(\mathrm{A}_{6}-4 \mathrm{H}\right)^{4-}$ anions showed highly variable abundances of ions that corresponded to $\left[\mathrm{M}^{\mathrm{II}}\left(\mathrm{A}_{6}-4 \mathrm{H}\right)\right]^{2-}$ and $\left[\mathrm{M}^{\mathrm{II}}\left(\mathrm{A}_{6}-5 \mathrm{H}\right)\right]^{3-}$, respectively (data not shown). Data shown in Figures 1, 2, and 3 were obtained with very careful isolation of the reagents before ion/ion reaction, and these results show little or no evidence of metal transfer to the hexa-dA and proton transfer from the hexa-dA to one of the phenanthroline ligand products. We therefore conclude that the signals consistent with $\left[\mathrm{M}^{\mathrm{II}}\left(\mathrm{A}_{6}-4 \mathrm{H}\right)\right]^{2-}$ and $\left[\mathrm{M}^{\mathrm{II}}\left(\mathrm{A}_{6}-5 \mathrm{H}\right)\right]^{3-}$ arise from ion/ion reactions of the next higher hexa-dA charge state that persist after the ion isolation step. It is also noteworthy that these products are largely absent when the reactions are conducted on a hybrid linear ion trap system (data not shown), which is consistent with there being deficiencies in the ion isolation procedures used in the hybrid quadrupole/ time-of-flight instrument.

\section{Preparation of $5^{\prime}-d\left(A_{6}\right)-3^{\prime}$ Solutions}

Oligodeoxynucleotide $5^{\prime}-\mathrm{d}\left(\mathrm{A}_{6}\right)-3^{\prime}$ was obtained from IDT (Coralville, IA) and used without further purification. Ultrapure water was provided from a NANOpure Infinity ultrapure water system (Barnstead/Thermolyne Corporation, Dubuque, IA). Oligodeoxynucleotide samples were diluted to a concentration of $55 \mu \mathrm{mol} \mathrm{L}^{-} 1(0.1$ $\mathrm{mg} \mathrm{mL}^{1} 1$ ) in water, and directly electrosprayed from this solution.

\section{Preparation of Solutions of Metal Complexes}

Preparation of $\left[M^{I I}(\text { phen })_{x}\right]^{2+}$ Where $M=C o, C u$, or Fe, and $x=2$ or 3

In many cases, preparation of the desired metal complex simply involved mixing of the appropriate metal salt and ligand in a methanolic solution to afford a final concentration of $0.1 \mathrm{mg} \mathrm{mL}{ }^{-1}$. Metal-phenanthroline solutions formed in this way generally produced both the bis- and tris-phen complexes with the transition metals upon nanospray ESI. Metal salts used for phenanthroline complexes were copper(II) nitrate hemi(pentahydrate), cobalt(II) chloride hexahydrate, iron(III) chloride hexahydrate, and iron(II) sulfate heptahydrate. These metal salts were obtained from Sigma-Aldrich (St. Louis, MO) 
a) $\left(\mathrm{A}_{6}-3 \mathrm{H}\right)^{3-}+\left[\mathrm{Cu} \text { (1) }(\text { phen })_{2}\right]^{2+}$
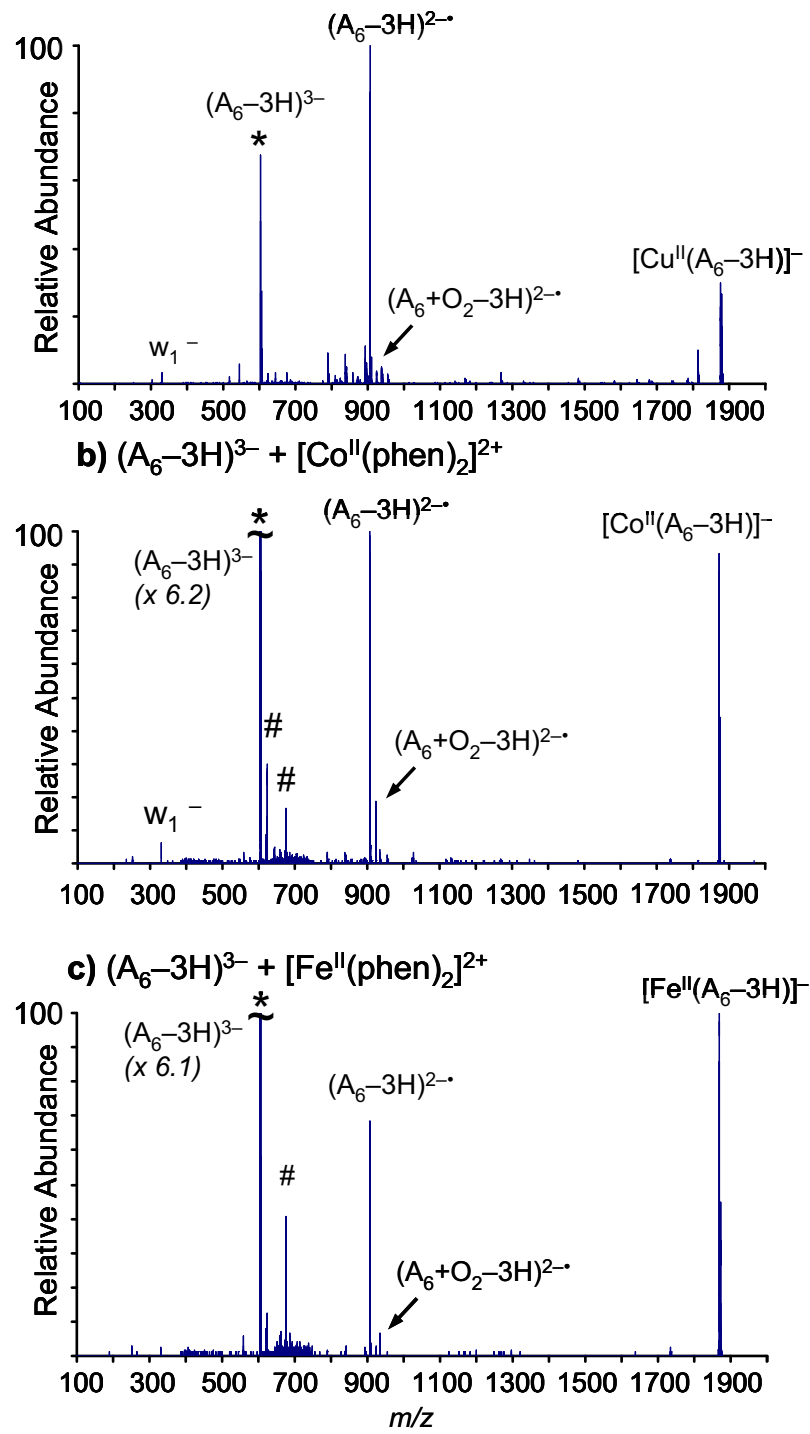

Figure 1. Negative post-ion/ion reaction product spectra for the reaction of $\left(\mathrm{A}_{6}-3 \mathrm{H}\right)^{3-}$ with (a) $\left[\mathrm{Cu}^{\mathrm{II}}(\text { phen })_{2}\right]^{2+}$, (b) $\left[\mathrm{CO}^{\mathrm{II}}\right.$ (phen $\left.)_{2}\right]^{2+}$, and (c) $\left[\mathrm{Fe}^{\mathrm{II}}(\mathrm{phen})_{2}\right]^{2+}$. The asterisk symbol indicates remaining precursor ion, the number symbol indicates ions that were observed in the pre-ion/ion spectra and are not the result of ion/ion reactions. All spectra are normalized to the most abundant product peak. The ion labeled $\mathrm{w}_{1}-$ refers to a sequence ion defined by the commonly used nomenclature [54].

and used without further purification. For example, mixing copper(II) nitrate hemipentahydrate $(\sim 0.1 \mathrm{mM})$ with three equivalents of 1,10-phenanthroline (SigmaAldrich) in methanol provided both the bis- and triscomplexes, $\left[\mathrm{Cu}^{\mathrm{II}}(\mathrm{phen})_{\mathrm{x}}\right]^{2+}(\mathrm{x}=2,3)$, upon nanospray ESI.

\section{Preparation of $\left[R u^{I I}(\text { phen })_{3}\right]\left(B F_{4}\right)_{2}$}

The ruthenium(II) tetrafluoroborate was received from Sioe See Volaric and used without further purification. Briefly, the ruthenium(II) tris-phenanthroline tetraflu- oroborate was synthesized by refluxing a mixture of ruthenium(III) chloride $(50 \mathrm{mg}$ ) (Sigma-Aldrich, Sydney, Australia) and 1,10-phenanthroline (180 mg) (SigmaAldrich) over a mercury/zinc amalgam. Following hot filtration, tetrafluoroboric acid $(50 \%, 0.5 \mathrm{~mL})$ was added to the filtrate and the solution was allowed to cool to room temperature to afford $\left[\mathrm{Ru}^{\mathrm{II}}(\mathrm{phen})_{3}\right]\left(\mathrm{BF}_{4}\right)_{2}$, which was used without further purification. Ruthenium solution for ESI was prepared by diluting $\left[\mathrm{Ru}^{\mathrm{II}}(\mathrm{phen})_{3}\right]\left(\mathrm{BF}_{4}\right)_{2}$ with methanol to a final concentration of $0.1 \mathrm{mg} \mathrm{mL}^{-1}$. It should be noted that this solution formed only the trisphen complex of $\mathrm{Ru}^{\mathrm{II}}$ under nano-ESI conditions.

\section{Preparation of $\left[M^{I I I}(\text { salen })\right]^{+}$}

Salen was prepared as reported previously [46]. Solutions of $\left[\mathrm{Fe}^{\mathrm{III}}(\text { salen })\right]^{+}$and $\left[\mathrm{Co}^{\mathrm{III}}(\text { salen })\right]^{+}$were formed on mixing stoichiometric quantities of iron(III) nitrate nonahydrate (Strem Chemicals, Newburyport, MA) or cobalt(II) chloride with salen in methanol.

\section{Computational Chemistry}

All calculations were conducted with the Gaussian03 suite of programs [47]. Geometry optimizations were
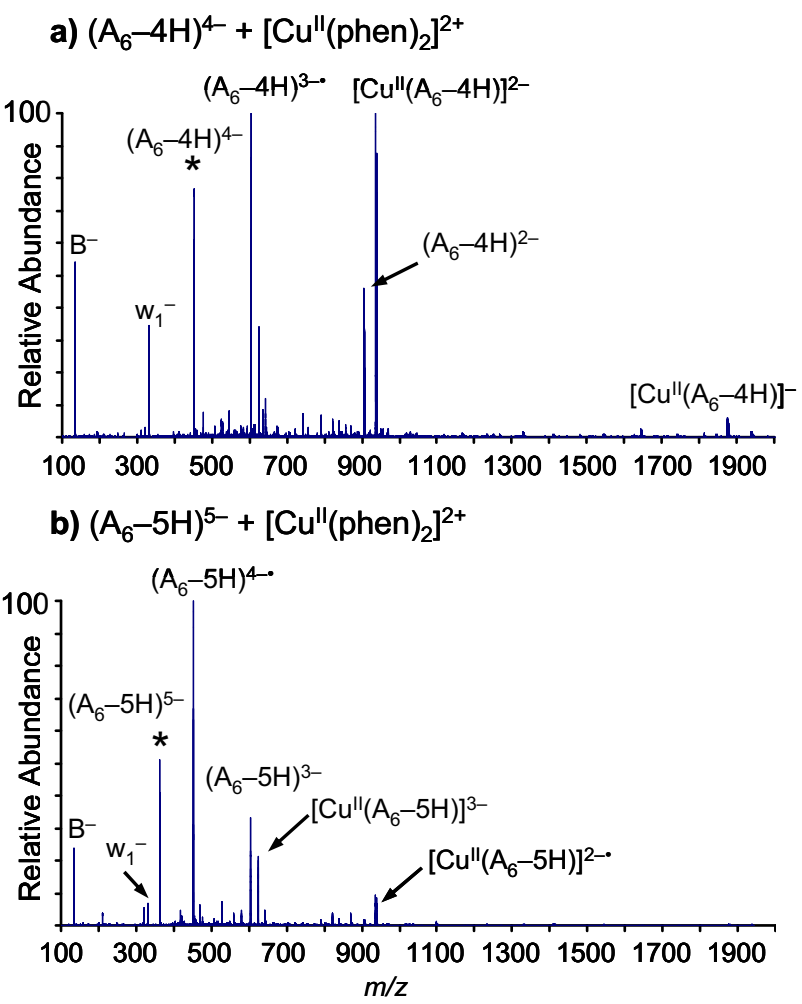

Figure 2. Negative post-ion/ion reaction product spectra for the reaction of $\left[\mathrm{Cu}^{\mathrm{II}}(\text { phen })_{2}\right]^{2+}$ with $(\mathbf{a})\left(\mathrm{A}_{6}-4 \mathrm{H}\right)^{4-}$ and $(\mathbf{b})$ $\left(\mathrm{A}_{6}-5 \mathrm{H}\right)^{5-}$. The asterisk symbol indicates remaining precursor ion. $\mathrm{B}^{-}$corresponds to the adenine anion, and $\mathrm{w}_{1-}$ refers to a sequence ion defined by the commonly used nomenclature. 

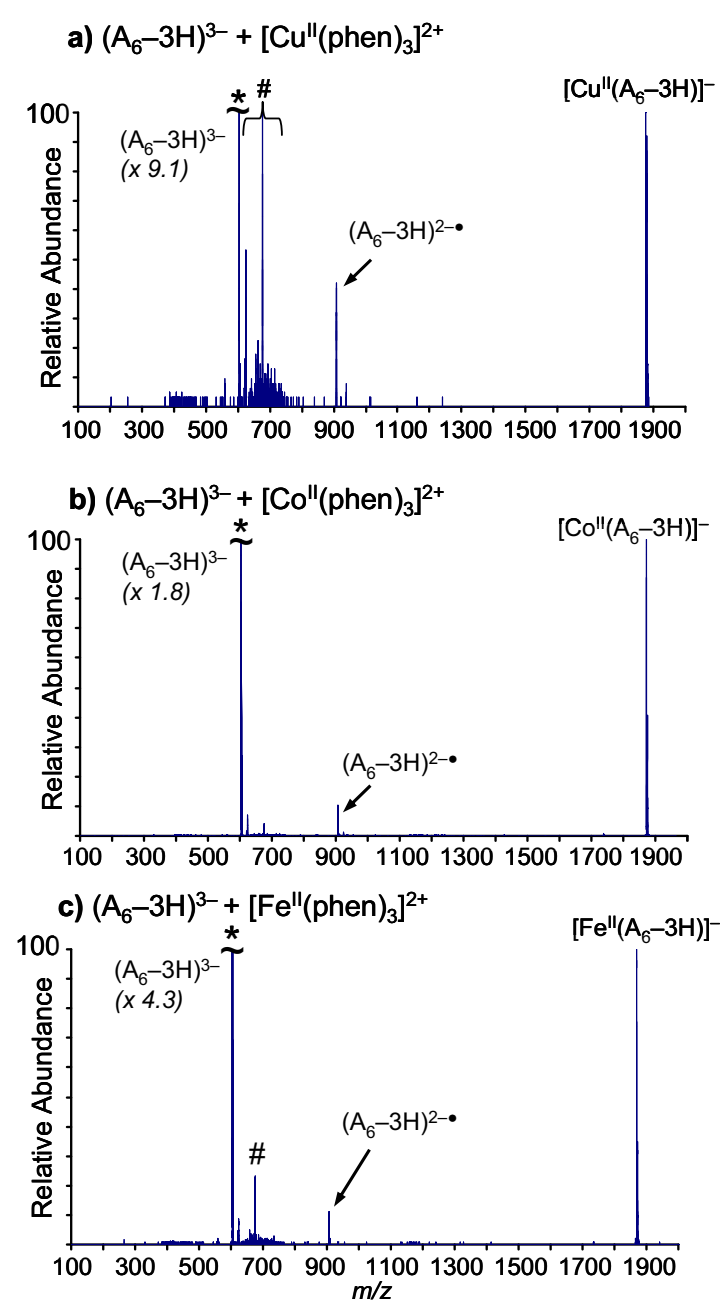

Figure 3. Negative post-ion/ion reaction product spectra for the reaction of $\left(\mathrm{A}_{6}-3 \mathrm{H}\right)^{3-}$ with (a) $\left[\mathrm{Cu}(\text { phen })_{3}\right]^{2+}$, (b) $\left[\mathrm{Co}(\text { phen })_{3}\right]^{2+}$, and (c) $\left[\mathrm{Fe}(\text { phen })_{3}\right]^{2+}$. The asterisk symbol indicates remaining precursor ion, the number symbol indicates ions that were observed in the pre-ion/ion spectra and are not the result of ion/ion reactions.

performed at the B3-LYP level of theory with a 6-31G $(d)$ basis set for $\mathrm{C}, \mathrm{H}, \mathrm{N}$, and $\mathrm{O}$, and the SDD basis set and effective core potential on the transition metals. Optimized structures were subjected to frequency calculations to ensure they corresponded to minima on their respective potential energy surfaces. It should be noted that in some cases it proved impossible to achieve convergence below the threshold for displacements. Full details are provided in Supplementary Material. In addition, the stability of the calculated wavefunction was tested using the stable keyword in G03 to ensure that the calculated wavefunction corresponded to the ground electronic state. The vertical recombination energy (RE) was calculated by optimizing the geometry in the +2 charge state and then performing a single point calculation at the same geometry for the +1 charge state. All complexes were assumed to be in their high spin state. Full details of optimized geometries and energies are provided as Supplementary Material.

\section{Results and Discussion}

\section{Reaction Phenomenology}

Figures 1-4 show results from selected ion/ion reactions, which are used to illustrate the different types of reactions observed between metal complex cations $\left(\left[\mathrm{M}^{\mathrm{II}}(\text { phen })_{\mathrm{x}}\right]^{2+}\right.$ where $\mathrm{x}=2$ or 3$)$ and the oligodeoxynucleotide anions, $\left(\mathrm{A}_{6}-\mathrm{nH}\right)^{\mathrm{n}-}$. The major first generation sets of products and the principal ion/ion reactions that give rise to them are listed numerically in Scheme 1. The arrows in the scheme are intended to contrast the possible competing reaction dynamics associated with the various sets of products. All the products may conceivably be formed via a long-lived (many vibrations) ion/ion reaction complex, $\left[\left(\mathrm{A}_{6}-\mathrm{nH}\right)^{\mathrm{n}-}-\left[\mathrm{M}^{\mathrm{II}}(\mathrm{phen})_{\mathrm{x}}\right]^{2+}\right]^{(\mathrm{n}-2)-*}$. Additionally, the products of reaction 1, corresponding to electrontransfer, may also arise via charge-transfer at a crossing point without proceeding through a long-lived complex. Previous ion/ion reaction studies involving multiply charged ions have suggested that charge-transfer at crossing points without long-lived complex formation can contribute significantly, in at least some cases, to electron-transfer [13-15]. Reactions 2 and 3, on the other hand, are expected to proceed via a long-lived complex. Reaction 2 corresponds to a net transfer of the divalent metal to the hexa-dA anion and requires the displacement of the phen ligands by groups within the hexa-dA. Reaction 3 corresponds to an adduct formation whereby the activated intermediate is stabilized (presumably by emission and collisional cooling in the ion trap) such that it survives detection. Fragmentation products attributable to the hexa-dA are sometimes observed but are not indicated in the scheme as these products are presumed to arise from the electrontransfer channel, as has been noted previously with other reagent cations [48-52].

In the case of the $\mathrm{Cu}(\mathrm{II}), \mathrm{Co}(\mathrm{II})$, and $\mathrm{Fe}(\mathrm{II})$ phenanthroline cation reactions, little or no attachment reaction 3 occurs for any of the hexa-dA charge states. Post ion/ion reaction spectra for the reactions between these complexes and $\left(\mathrm{A}_{6}-3 \mathrm{H}\right)^{3-}$ are provided in Figure 1. Peaks corresponding to charge reduced hexa-dA anions (denoted as $\left(\mathrm{A}_{6}-3 \mathrm{H}\right)^{2-\cdot}$ ) that arise from electron-transfer reaction [1] are observed in all the product spectra. The electrontransfer product is most prominent in the reaction with $\left[\mathrm{Cu}(\text { phen })_{2}\right]^{2+}$ but makes smaller relative contributions to the spectra derived from reactions with $\left[\mathrm{Fe}^{\mathrm{II}}\right.$ $\left.(\text { phen })_{2}\right]^{2+}$ and $\left[\mathrm{Co}^{\mathrm{II}}(\text { phen })_{2}\right]^{2+}$. The other major ion/ion reaction channel noted corresponds to reaction 2 , which leads to transition-metal ion incorporation into the hexa-dA. Note that a doubly charged product ion is also observed at $m / z=922.7$ for all of the reagents in reaction with the $\left(\mathrm{A}_{6}-3 \mathrm{H}\right)^{3-}$ species. This ion does not correspond to a fragment ion of the hexa- $\mathrm{dA}$, as its mass is greater than that of the intact doubly charged molecule. The mass is also independent of metal ion, which precludes the possibility that this is a complex between 

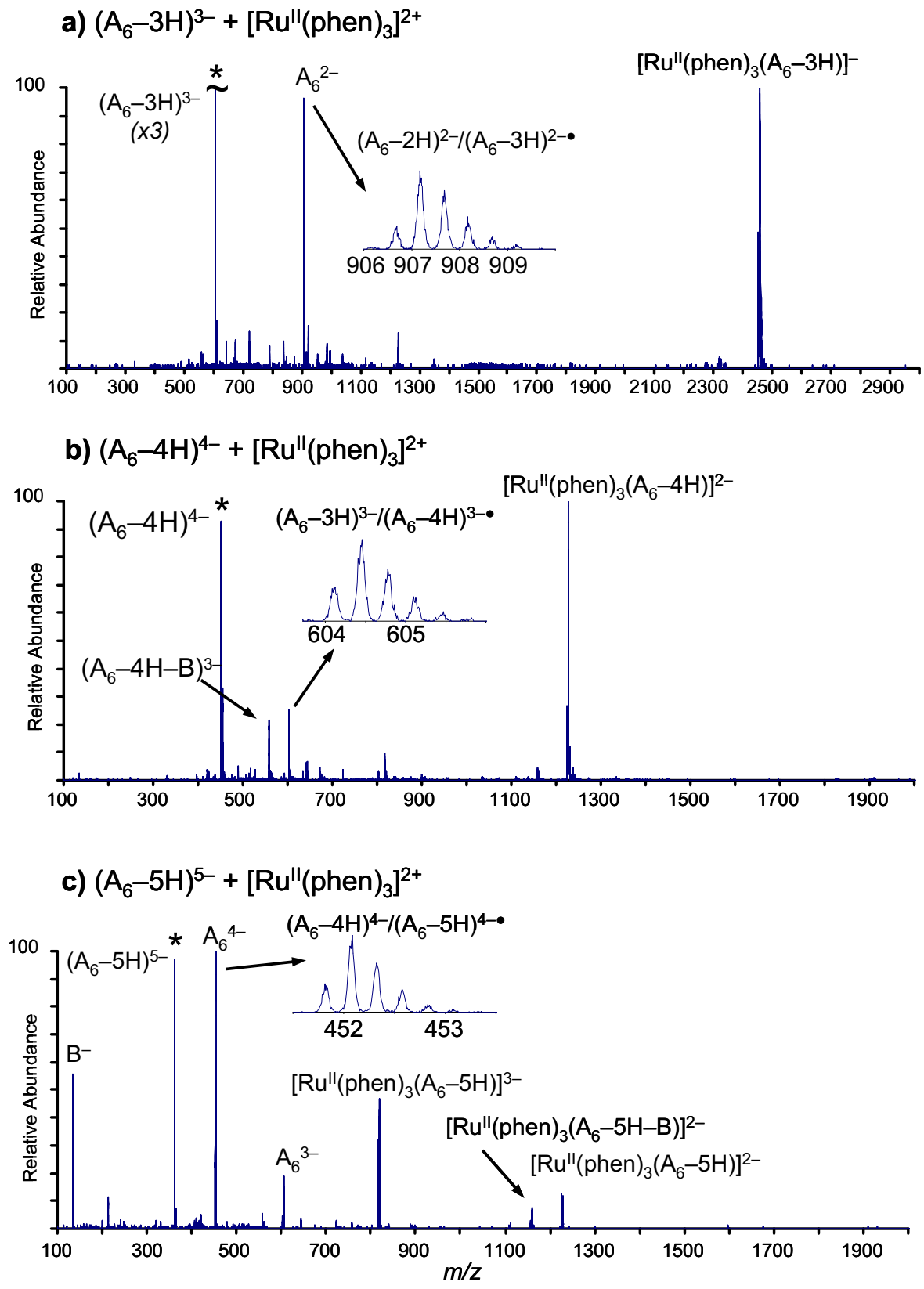

Figure 4. Negative post-ion/ion reaction product spectra for the reaction of $\left[\mathrm{Ru}^{\mathrm{II}}(\text { phen })_{3}\right]^{2+}$ with (a) $\left(\mathrm{A}_{6}-3 \mathrm{H}\right)[3],(\mathbf{b})\left(\mathrm{A}_{6}-4 \mathrm{H}\right)^{4-}$, and $(\mathbf{c})\left(\mathrm{A}_{6}-5 \mathrm{H}\right)^{5-}$. The asterisk symbol indicates remaining precursor ion. $\mathrm{B}-$ corresponds to the adenine anion. The inserts show that charge reduction of the hexa-dA occurs via both proton and electron-transfer, although proton transfer is believed to arise from reaction with back-ground neutrals.

the metal ion and part of the hexa-dA. In addition, there is no evidence in the positive post-ion/ion reaction product spectrum (data not shown) for the transfer of part of a phenanthroline ligand to hexa-dA. The most likely interpretation is that this species arises from attachment of molecular oxygen to the $\left(\mathrm{A}_{6}-3 \mathrm{H}\right)^{2-}$ anion radical. Oxygen attachment to peptide radical cations formed via ion/ion electron-transfer has recently been noted in the apparatus used in these studies [53].

For all hexa-dA charge states, proton transfer to the $\left(\mathrm{A}_{6}-\mathrm{nH}\right)^{\mathrm{n}-}$ species to yield the $\left(\mathrm{A}_{6}-(\mathrm{n}-1) \mathrm{H}\right)^{(\mathrm{n}-1)-}$ ion leads to signals that overlap with the isotope peaks associated with the $\left(\mathrm{A}_{6}-\mathrm{nH}\right)^{(\mathrm{n}-1)-\cdot}$ ion. Deconvolution of these envelopes enables quantification of the contribution from each product set. The contribution of proton transfer to the charge reduction of $\left(\mathrm{A}_{6}-\mathrm{nH}\right)^{\mathrm{n}-}$ increases with $\mathrm{n}$. That is, it is least prominent with the $\left(\mathrm{A}_{6}-3 \mathrm{H}\right)^{3-}$ ion and most prominent with the $\left(\mathrm{A}_{6}-5 \mathrm{H}\right)^{5-}$ species. The proton transfer product apparently arises exclusively from ion/ molecule reactions with species present in the background gas. Direct evidence for proton transfer via an ion/ion reaction is absent. Specifically, the $\left[\mathrm{M}^{\mathrm{II}}(\text { phen })_{(\mathrm{x}-1}\right)($ phen- 


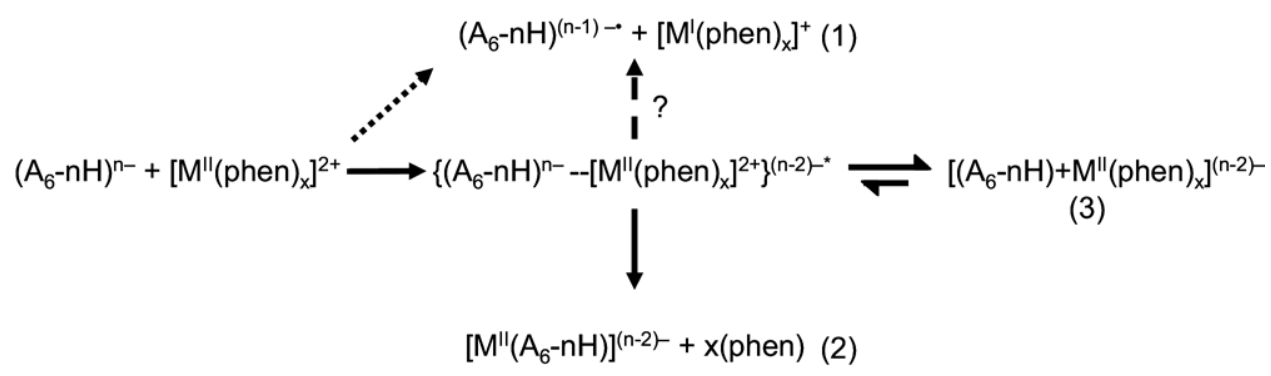

(1) Electron transfer from the hexa-dA anion.

(2) Metal transfer to the hexa-dA anion.

(3) Cation/anion attachment.

Scheme 1. A summary of the major first generation ion/ion reactions of $\left[\mathrm{M}^{\mathrm{II}}(\mathrm{phen}) \mathrm{x}^{2+}\right.$ where $(\mathrm{x}=$ 2 or 3) species with hexa-dA anions.

$\mathrm{H})]^{+}$ion, which would represent the positive ion partner of $\left.\left[\mathrm{A}_{6}-(\mathrm{n}-1) \mathrm{H}\right]^{(\mathrm{n}-1}\right)-$ if proton transfer occurred in an ion/ion reaction, is absent from the corresponding positive mode post-ion/ion spectra (data not shown). Furthermore, ion/ion reactions using cationic reagents comprised of fully deuterated phenanthroline showed no evidence for deuteron transfer (data not shown). Control experiments where the isolated hexa-dA anions were stored without cations but under identical conditions to those used for ion/ion reactions showed ionmolecule proton transfer reactions occurring with the rates of these reactions following the trend $\left(\mathrm{A}_{6}-5 \mathrm{H}\right)^{5-}$ $\gg\left(\mathrm{A}_{6}-4 \mathrm{H}\right)^{4-}>\left(\mathrm{A}_{6}-3 \mathrm{H}\right)^{3-}$ (data not shown). No effort was made to attempt to identify the adventitious neutral proton donors present in the vacuum system.

Reactions of the $\left(\mathrm{A}_{6}-4 \mathrm{H}\right)^{4-}$ and $\left(\mathrm{A}_{6}-5 \mathrm{H}\right)^{5-}$ ions proceed via the same generic reactions as the $\left(\mathrm{A}_{6}-3 \mathrm{H}\right)^{3-}$ anions shown in Scheme 1, although the relative partitioning between channels differs (see Figure 2 for data collected with $\left[\mathrm{Cu}^{\mathrm{II}}(\text { phen })_{2}\right]^{2+}$ and Table $1)$. There tends to be a greater degree of fragmentation of the hexa-dA for both the $\left(\mathrm{A}_{6}-4 \mathrm{H}\right)^{4-}$ and $\left(\mathrm{A}_{6}-5 \mathrm{H}\right)^{5-}$ ions than for $\left(\mathrm{A}_{6}-3 \mathrm{H}\right)^{3-}$. Fragmentation associated with ion/ion electron-transfer from ODN anions has been reported previously [45]. For a given reaction time and a given number of cationic reagents the possibility of contributions due to sequential ion/ion reactions involving the anions increases with anion charge state, as the reaction rates are proportional to the product of the squares of the reaction charges [18]. Hence, some product ions correspond to sequential ion/ion events. For example, the post ion/ion spectrum of [Cu ${ }^{\text {II }}$ (phen $\left.)_{2}\right]^{2+}$ and $\left(\mathrm{A}_{6}-4 \mathrm{H}\right)^{4-}$ (Figure 2a) shows product ions corresponding to $\left(\mathrm{A}_{6}-4 \mathrm{H}\right)^{2-}$. This product arises from sequential ion/ion electron-transfer reactions, as determined from selective ejection of the intermediate $\left(\mathrm{A}_{6}-4 \mathrm{H}\right)^{3-\cdot}$ ion (data not shown). Likewise, products that may only be readily rationalized as arising from sequential ion/ion reactions are also apparent following reaction of the $\left(\mathrm{A}_{6}-5 \mathrm{H}\right)^{5-}$ species (see Figure $2 \mathrm{~b}$ ). For example, the $\left(\mathrm{A}_{6}-5 \mathrm{H}\right)^{3-}$ ion can be accounted for by two successive electron-transfer reactions, and the
$\left[\mathrm{Cu}^{\mathrm{II}}\left(\mathrm{A}_{6}-5 \mathrm{H}\right)\right]^{2-}$ species can be rationalized as resulting from independent electron-transfer (reaction 1) and metal transfer reactions (reaction 2). Those species indicated as second generation ion/ion reaction products also show different time-dependent abundance changes than the first generation ion/ion reaction products (i.e., the second generation products continue to increase in relative abundance when the first generation products begin to show a decrease in abundance).

Reactions of the tris-phen complexes, $\left[\mathrm{M}^{\mathrm{II}}(\mathrm{phen})_{3}\right]^{2+}$, for $\mathrm{M}=\mathrm{Cu}, \mathrm{Co}$, and $\mathrm{Fe}$, with the hexa-dA anions proceed through the same primary pathways as the corresponding bis-phen complexes and the relative contributions of reactions 1 and 2 are summarized in Table 1. Results of ion/ion reactions between $\left(\mathrm{A}_{6}-3 \mathrm{H}\right)^{3-}$ and tris-phen complexes are shown in Figure 3. Inspection of Table 1 reveals a significant difference between the bis- and tris-phen complexes, in the relative extents of electron and metal transfer (Figure 3). Specifically, the extent of electron-transfer is significantly diminished in the tris-phen complexes compared with their corresponding bis-phen counterparts. Indeed, not only is electron-transfer less prominent when comparing the tris-phen complex with the bis-phen complex for a particular metal and charge state of hexa-dA, but the proportion of electron-transfer upon reaction with any of the tris-phen complexes is less than with any of the bis-phen complexes for a particular charge state of hexa-dA.

In addition to the cationic complexes examined above, we have also examined $\left[\mathrm{Ru}^{\mathrm{II}}(\text { phen })_{3}\right]^{2+}$. In contrast to the complexes discussed above, reaction with the hexa-dA anions results in competition between electron-transfer (reaction 1) and complex formation (reaction 3). Metal transfer (reaction 2) does not make a significant contribution to the ion/ion chemistry of the $\mathrm{Ru}^{\mathrm{II}}$ complex. The formation of a complex between the two reagent ions is readily rationalized as occurring through an intimate collision between the two reagent ions in which the long-lived excited complex thus formed may then undergo relaxation (either through collisional deactivation or radiative emission). In con- 
trast, the first row transition-metal phenanthroline complexes discussed above are assumed to undergo rapid elimination of the neutral phenanthroline ligands upon the formation of such a complex. It is interesting to note in this context that a striking feature of the chemistry of ruthenium(II) is its comparatively high kinetic stability to substitution compared with kinetically labile transition metals such as those studied here [55]. This result provides a clear example of the identity of the transitionmetal having a dominant influence in directing the chemistry following an ion/ion reaction.

It is clear from the results described above that incorporation of the metal ion into the oligonucleotide with concomitant ligand loss takes place with little or no competition from oligonucleotide fragmentation. In fact, the only instances where there is clear evidence for oligonucleotide fragmentation in conjunction with cation/anion attachment is in the reactions of $\left[\mathrm{Ru}^{\mathrm{II}}\right.$ (phen $\left.)_{3}\right]^{2+}$ with $\left(\mathrm{A}_{6}-4 \mathrm{H}\right)^{4-}$ and $\left(\mathrm{A}_{6}-5 \mathrm{H}\right)^{5-}$. Relatively small signals are observed for loss of neutral adenine from the $\left[\mathrm{Ru}^{\mathrm{II}}(\mathrm{phen})_{3}\left(\mathrm{~A}_{6}-4 \mathrm{H}\right)\right]^{2-}$ complex and loss of the adenine anion from the $\left[\mathrm{Ru}^{\mathrm{II}}(\text { phen })_{3}\left(\mathrm{~A}_{6}-5 \mathrm{H}\right)\right]^{3-}$ complex (see Figure $4 b$ and $c$, respectively). Hence, oligonucleotide fragmentation is competitive only when the ligand displacement channel is inhibited. Even in this instance, however, fragmentation of the oligonucleotide is a minor process. This is consistent with previous ion/ion reaction studies involving protein anions and cations that show no covalent bond cleavage associated with anion/cation complex formation [19]. It is apparent that the lifetimes of the anion/ cation complexes are sufficiently large and the cooling processes are sufficiently fast to enable observation of the stabilized complexes noted in Figure 4. When particularly facile dissociation channels are present, as is apparently the case for ligand losses from the $\mathrm{Fe}^{\mathrm{II}}, \mathrm{Cu}^{\mathrm{II}}$, and $\mathrm{Co}^{\mathrm{II}}$ complexes, no evidence for the intermediate complex is observed. Perhaps the key difference is that ligand loss is very likely to be a displacement reaction in which new interactions with the metal ion occur in conjunction with the loss of interaction with the ligand. Hence, in contrast with covalent bond dissociation associated with base loss, which is expected to endoergic by roughly $1 \mathrm{eV}$ [56], the displacement reaction for the $\mathrm{Fe}^{\mathrm{II}}, \mathrm{Cu}^{\mathrm{II}}$, and $\mathrm{Co}^{\mathrm{II}}$ complexes (but not for the $\mathrm{Ru}^{\mathrm{II}}$ complex) may require much less energy and, in fact, may very well be exoergic.

Reactions between the hexa-dA anions and both Fe $\mathrm{Fe}^{\mathrm{III}}$ and $\mathrm{Co}^{\mathrm{III}}$ complexes with the di-anionic Schiff base ligand salen $\left(\left[\mathrm{Fe}^{\mathrm{III}}(\text { salen })\right]^{+}\right.$and $\left[\mathrm{Co}^{\mathrm{III}}(\text { salen })\right]^{+}$) have also been examined (see Supplementary Figure S1 for selected spectra). Scheme 2 shows the reactions that compete during ion/ion reactions of $\left[\mathrm{M}^{\mathrm{II}} \text { (salen) }\right]^{+}$and hexa-dA anions. Post ion/ion reaction spectra show products corresponding to electron-transfer (reaction 4), metal transfer to the hexa-dA (reaction 5), and formation of a ternary complex between the hexa-dA and the metal-salen complex (reaction 6). These reactions are largely analogous to reactions $1-3$ summarized

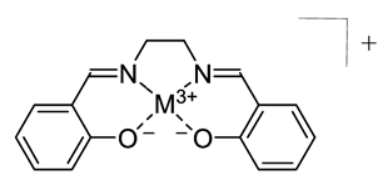

$\left[\mathrm{M}^{\mathrm{III}}(\text { salen })\right]^{+}$

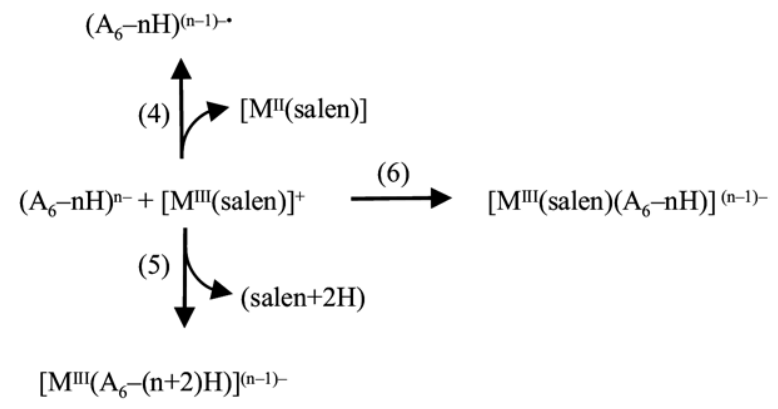

Scheme 2. Reaction scheme for [MIII(salen)]+ complexes and hexa-dA anions.

in Scheme 1 for the $\left[\mathrm{M}^{\mathrm{II}}(\mathrm{phen})_{\mathrm{x}}\right]^{2+}$ cations, although in the case of metal transfer, elimination of the salen ligand as a neutral species requires the transfer of two protons from the hexa-dA anion. As the hexa-dA is essentially a pentaprotic acid (due to the five phosphodiester groups on the backbone), the ternary complexes formed upon reactions with $\left(\mathrm{A}_{6}-4 \mathrm{H}\right)^{4-}$ and $\left(\mathrm{A}_{6}-5 \mathrm{H}\right)^{5-}$ do not lead to the elimination of a neutral salen ligand, unlike the $\left(\mathrm{A}_{6}-3 \mathrm{H}\right)^{3-}$ species, but rather to abundant product ion peaks corresponding to the ternary complexes. In contrast to the behavior of the $\left[\mathrm{Fe}^{\mathrm{III}}(\text { salen })\right]^{+}$ions, reaction between $\left[\mathrm{Co}^{\mathrm{III}}(\text { salen })\right]^{+}$, and $\left[\mathrm{A}_{6}-3 \mathrm{H}\right]^{3-}$ leads to noticeably less elimination of the salen ligand. Rather, a relatively intense ternary complex peak is observed. The cobalt complexes also typically lead to a greater proportion of electron-transfer than their ferrous counterparts. Cobalt(III) is far more kinetically inert to substitution than iron(III) [57] and this is apparently also reflected in the gas-phase ion/ion reaction chemistry.

\section{Qualitative Trends in Product Partitioning}

The reactions of the $\left[\mathrm{Cu}^{\mathrm{II}}(\text { phen })_{\mathrm{x}}\right]^{2+},\left[\mathrm{Co}^{\mathrm{II}}(\text { phen })_{\mathrm{x}}\right]^{2+}$, $\left[\mathrm{Fe}^{\mathrm{II}}(\mathrm{phen})_{\mathrm{x}}\right]^{2+}(\mathrm{x}=2,3)$ species with the hexa-dA anions are largely partitioned into the two channels leading to products 1 and 2 indicated in Scheme 1 . Table 1 summarizes the relative abundances of the primary product anions from these two processes. This summary highlights several general trends that are relevant to the use of ion/ion reactions for forming different types of hexa-dA product ions. The general tendency for the electron-transfer channel is that, for a given metal, it is more prevalent for the reagent complexes in which two, rather than three, phenanthroline ligands are coordinated to the metal. For a given number of ligands, the copper complexes undergo more electrontransfer than their corresponding cobalt or iron coun- 
terparts. There does not appear to be a clear trend in the extent of electron-transfer with increasing hexa-dA charge state, however. In general, for a given reagent cation, more electron-transfer relative to metal transfer is observed from the $\left(\mathrm{A}_{6}-5 \mathrm{H}\right)^{5-}$ charge state than either the $\left(\mathrm{A}_{6}-4 \mathrm{H}\right)^{4-}$ or $\left(\mathrm{A}_{6}-3 \mathrm{H}\right)^{3-}$ charge states, with the only exception that $\left[\mathrm{Cu}^{\mathrm{II}}(\text { phen })_{2}\right]^{2+}$ shows the same amount of electron-transfer reaction with $\left(\mathrm{A}_{6}-3 \mathrm{H}\right)^{3-}$ and with $\left(\mathrm{A}_{6}-5 \mathrm{H}\right)^{5-}(0.71 \pm 0.05$ for both these anions $)$. There tends to be more electron-transfer with the bisphen cations with the $\left(\mathrm{A}_{6}-3 \mathrm{H}\right)^{3-}$ anion than with the $\left(\mathrm{A}_{6}-4 \mathrm{H}\right)^{4-}$ anion (see Table 1$)$.

If it is assumed that electron-transfer (et) occurs exclusively at an avoided crossing and that metal ion incorporation occurs exclusively via the break-up of a long-lived chemical complex formed by a "hardsphere" (hs) collision, it is possible to predict, at least qualitatively, the expected partitioning between the two channels based on estimated cross-sections for the two processes. The cross section $(\sigma)$ for each of these two-body interactions is given by

$$
\sigma_{r x n}=P_{r x n} \pi b_{r x n}^{2}
$$

where $\mathrm{P}_{\text {rxn }}$ is the probability of reaction at classical impact parameters $b_{\text {rxn }}$.

The square of the impact parameter of each of these interactions (in atomic units) takes the form [58]:

$$
b_{r x n}^{2}=r_{r x n}^{2}\left[1+\frac{2\left|Z_{1} Z_{2}\right|}{r_{r x n} \mu \nu_{r e l}^{2}}\right]
$$

where $Z_{1}$ and $Z_{2}$ are the unit charges of the reagent ions; $\nu_{\text {rel }}$ is the relative velocity of the ions; $\mu$ is the reduced mass, and $r_{r x n}$ is the reaction distance. In the case of the hard-sphere collision, $\mathrm{r}_{\mathrm{hs}}$ can be estimated from the sum of the radii of the reactants. In the case of electrontransfer, an estimate for $r_{e t}$ can be taken as the distance at which the ground state curves of the entrance and exit channels cross, which, in atomic units, is given by:

$$
r_{e t} \approx \frac{\left(Z_{1} Z_{2}-Z_{3} Z_{4}\right)}{\Delta H_{e t}}
$$

where $Z_{1}$ and $Z_{2}$ are the unit charges of the reactions, $Z_{3}$ and $Z_{4}$ are the unit charges of the products, and $\Delta \mathrm{H}_{\mathrm{et}}$ is given by

$$
\Delta \mathrm{H}_{\mathrm{et}}=\mathrm{EA}\left(\left(\mathrm{A}_{6}-\mathrm{nH}\right)^{(\mathrm{n}-1)-\cdot}\right)-\mathrm{RE}\left(\left[\mathrm{M}^{\mathrm{II}}(\text { phen })_{x}\right]^{2+}\right)
$$

where EA represents electron affinity and RE represents recombination energy.

In the case of the hard-sphere collision, $\mathrm{P}_{\mathrm{hs}}$ can be assumed to approach unity such that the cross-section for complex formation can be estimated from $\pi \mathrm{b}_{\mathrm{hs}}^{2}$. The probability for electron-transfer at the point at which the entrance and exit channels cross, $\mathrm{P}_{\mathrm{et}}$, on the other hand, requires use of a model for the probability of transition between adiabatic states. A commonly used approach is based on Landau-Zener theory $[59,60] . \mathrm{P}_{\text {et }}$ is determined by the non-adiabatic transition probability between states at the avoided crossing, $\mathrm{P}_{\mathrm{LZ}}$, by the relation:

$$
P_{e t}=2 P_{L Z}\left(1-P_{L Z}\right)
$$

The expression for $\mathrm{P}_{\mathrm{LZ}}$ is:

$$
P_{L Z}=\exp \left(\frac{2 \pi H_{12}^{2}}{\frac{d r}{d t}\left(\frac{Z_{1} Z_{2}}{r_{e t}^{2}}-\frac{Z_{3} Z_{4}}{r_{e t}^{2}}\right)}\right)
$$

where $\mathrm{H}_{12}$ is the coupling matrix element at the point of closest approach, $\mathrm{dr} / \mathrm{dt}$ is the radial velocity of the reactants at the crossing point, and the remainder of the denominator gives the differences in the slopes of the entrance and exit channels at the crossing point. The radial velocity at the crossing point can be estimated by:

$$
\frac{d r}{d t} \approx\left[\frac{2\left|Z_{1} Z_{2}\right|}{r_{e t} \mu}\right]^{0.5}
$$

The coupling matrix element, which indicates the strength of the electronic coupling between states, is extremely difficult to determine a priori for such large systems. A parameterized expression for $\mathrm{H}_{12}$ described by Olson and coworkers [61, 62] and based on data collected for the reactions of a number of relatively small singly charged ions was used recently in an examination of parameters that affect proton transfer and electron-transfer in ion/ion reactions of polypeptide cations [20]. This expression allows for an estimation of the coupling matrix based upon EA and RE values:

$$
H_{12}=(1.044 \sqrt{E A} \sqrt{R E x}) \cdot \exp (-0.875 x)
$$

where

$$
x=\frac{r_{e t}}{2}(\sqrt{2 E A}+\sqrt{2 R E})
$$

With the relationships just presented and parameters that are either known or can be estimated, it is possible to examine the dependence of the fractional contribution of electron-transfer upon cation RE, anion EA, and reactant ion charges predicted by this model. For example, the fraction of electron-transfer products can be estimated by

$$
\frac{\sigma_{e t}}{\sigma_{t o t}} \approx \frac{P_{e t} \pi b_{e t}^{2}}{P_{e t} \pi b_{e t}^{2}+\left(1-P_{e t}\right) \pi b_{h s}^{2}}
$$

The electron-transfer cross-section is based on a point charge model such that the use of $r_{e t}$ for $r_{r \times n}$ in 
Table 2. B3-LYP/6-31G $(d)$ vertical recombination energies $(\mathrm{eV})$

\begin{tabular}{lcc}
\hline \multicolumn{1}{c}{ Complex } & $\begin{array}{c}\text { Point } \\
\text { group }\end{array}$ & $\begin{array}{c}\text { Vertical recombination } \\
\text { energy }(\mathrm{eV})\end{array}$ \\
\hline \hline$\left[\mathrm{Cu}(\text { phen })_{2}\right]^{2+}$ & $\mathrm{D}_{2}$ & 8.4 \\
{$\left[\mathrm{Co}(\text { phen })_{2}\right]^{2+}$} & $\mathrm{D}_{2} \mathrm{~d}$ & 7.4 \\
$\left.[\mathrm{Fe} \text { (phen) }]_{2}\right]^{2+}$ & $\mathrm{D}_{2} \mathrm{~d}$ & 7.4 \\
{$\left[\mathrm{Cu}(\text { phen })_{3}\right]^{2+}$} & $\mathrm{C}_{1}$ & 6.9 \\
$\left.[\mathrm{Co} \text { (phen) }]_{3}\right]^{2+}$ & $\mathrm{D}_{3}$ & $6.5^{\mathrm{a}}$ \\
$\left.[\mathrm{Fe} \text { (phen) }]_{3}\right]^{2+}$ & $\mathrm{D}_{3}$ & $6.3^{\mathrm{a}}$ \\
\hline
\end{tabular}

${ }^{\text {a }}$ Fails to converge on the displacement criteria.

relation 2 for the determination of $b_{\text {et }}^{2}$ and the use of $r_{h s}$ for $\mathrm{r}_{\mathrm{rxn}}$ in relation 2 in determining $\mathrm{b}_{\mathrm{hs}}^{2}$ effectively places the point charges at the centers of the reactants. This is clearly an oversimplification, particularly for the hexa- $\mathrm{dA}$ anions, and is expected to give rise to an underestimation of the electron-transfer channel. Another approximation is to use the following relation for the square of the electron-transfer impact parameter:

$$
b_{e t}^{2}=\left(r_{e t}+r_{h s}\right)^{2}\left[1+\frac{2\left|Z_{1} Z_{2}\right|}{r_{e t} \mu \nu_{r e l}^{2}}\right]
$$

This approximation effectively places the point charges on the surfaces of the ions closest to one another. This approximation is likely to overestimate the electron-transfer contribution. Given the uncertainties in several of the other parameters used in the model, a more sophisticated set of assumptions regarding the charge locations is probably unjustified. In any case, similar trends are expected with any set of assumptions regarding the charge distribution within the ions.

The two main parameters in the $\mathrm{H}_{12}$ expression are the relevant values of EA and RE. These values are also important in determining $\mathrm{r}_{\mathrm{et}}$. The computed REs for the bis- and tris-phenanthroline complexes of $\mathrm{Cu}^{\mathrm{II}}, \mathrm{Co}^{\mathrm{II}}$, and $\mathrm{Fe}^{\mathrm{II}}$ are listed in Table $2[63,64]$. The REs for the bis-phenanthroline complexes are greater than the corresponding tris-phenanthroline complexes and, within each set of complexes with the same ligand number, the $\mathrm{RE}$ follows the order $\mathrm{Cu}>\mathrm{Co} \approx \mathrm{Fe}$.

The EA values of the hexa-dA anions are expected to decrease with the increase of absolute charge due to the destabilizing electrostatic field $[65,66]$. Indeed, recent photo-electron spectroscopy studies by Kappes and coworkers on $\left(\mathrm{A}_{5}-4 \mathrm{H}\right)^{4-}$ demonstrate the fourth vertical electron affinity to be $0.11 \mathrm{eV}$ (the adiabatic electron affinity was reported to be slightly negative) $[65,66]$. Hence the EA values of the hexa-dA charge states studied here can be expected to be small for the $\left(\mathrm{A}_{6}-3 \mathrm{H}\right)^{3-}$ species and to decrease or even be negative for the $\left(\mathrm{A}_{6}-4 \mathrm{H}\right)^{4-}$ and $\left(\mathrm{A}_{6}-5 \mathrm{H}\right)^{5-}$ species. Unfortunately, the approximation for $\mathrm{H}_{12}$ cannot accommodate EA values less than or equal to zero and is not expected to fit well for EA values of less than about $0.3 \mathrm{eV}$.

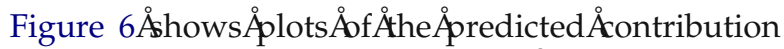
from electron-transfer for the $\left(\mathrm{A}_{6}-3 \mathrm{H}\right)^{3-}$ anion derived from relation 9 using $\mathrm{r}_{\mathrm{et}}^{2}$ in relation 2 (dashed curve) and using relation 10 (solid curve) as a function of cation recombination energy. The plot also shows the individual data points of the measured contribution of electron-transfer for each of the $\left[\mathrm{M}^{\mathrm{II}}(\text { phen })_{\mathrm{x}}\right]^{2+}$ for $\mathrm{M}=\mathrm{Cu}$, $\mathrm{Co}$, or $\mathrm{Fe}$, and $\mathrm{x}=2$ or 3 metal complexes studied. The calculation was based on the following parameters: 300 $\mathrm{K}$ ions, a cation mass of $450 \mathrm{Da}$, an anion mass of 1800 $\mathrm{Da}$, cation hard-sphere cross-section of $150 \AA^{2}$, anion hard-sphere cross-section of $400 \AA^{2}$, and anion electron affinity of $1.0 \mathrm{eV}$. In the case of constant electron affinity, reaction exothermicity increases directly with RE. (Note that there is experimental and theoretical support for minimal internal heating of polyatomic ions by the electrodynamic field of the ion trap, provided that they are not stored close to a stability boundary

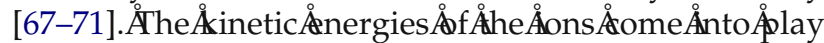
in the model via the relative velocity term in relation 2 . When comparing the relative partitioning between ion/ ion reaction channels, the relative velocity term tends to cancel because it is present for all channels. Hence, the

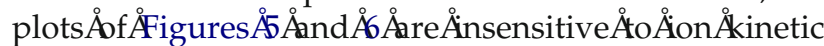
temperature over many thousands of degrees.) The two approaches to determining $b_{\mathrm{et}}^{2}$ show the same qualitative dependence upon recombination energy but, as expected, the approximation that places the assumed point charges at the ion centers (dashed curve) leads to a smaller contribution from electron-transfer than does the placement of point charges at the ion surfaces. For this case, a broad maximum is noted for $\sigma_{\text {et }} / \sigma_{\text {tot }}$ over the range of $\mathrm{RE}=8-9.5 \mathrm{eV}$. This suggests that the recombination energy and, therefore, the reaction exothermicity, can be either too low or too high for electron-transfer to occur. However, the model assumes

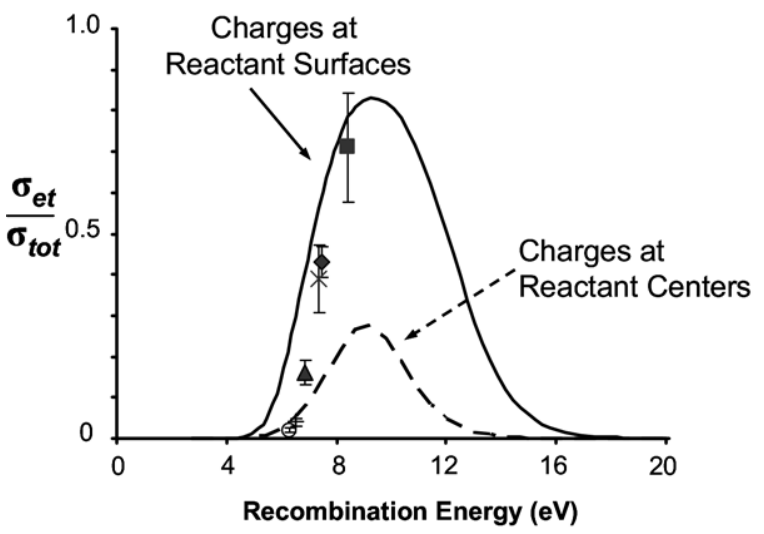

Figure 5. Predicted contribution from electron-transfer for the $\left(\mathrm{A}_{6}-3 \mathrm{H}\right)^{3-}$ anion as a function of recombination energy (in $\mathrm{eV}$ ). The solid line represents the contribution to electron-transfer if the charges are assumed to be at the reactant surfaces, while the dashed line represents the contribution to electron-transfer if the charges are assumed to be at the reactant centers. The data symbols indicate the measured fraction of electron-transfer product for each metal complex $\left[\mathrm{Cu}^{\mathrm{II}}(\mathrm{phen})_{2}\right]^{2+}$ (filled square), [Co ${ }^{\mathrm{II}}$ (phen $\left.)_{2}\right]^{2+}$ (filled diamond), $\left[\mathrm{Fe}^{\mathrm{II}}(\text { phen })_{2}\right]^{2+}$ (multiplication symbol), $\left[\mathrm{Cu}^{\mathrm{II}}(\text { phen })_{3}\right]^{2+}$ (filled triangle), $\left[\mathrm{Co}^{\mathrm{II}}(\mathrm{phen})_{3}\right]^{2+}$ (plus symbol), $\left[\mathrm{Fe}^{\mathrm{II}}(\mathrm{phen})_{3}\right]^{2+}$ (open circle). 


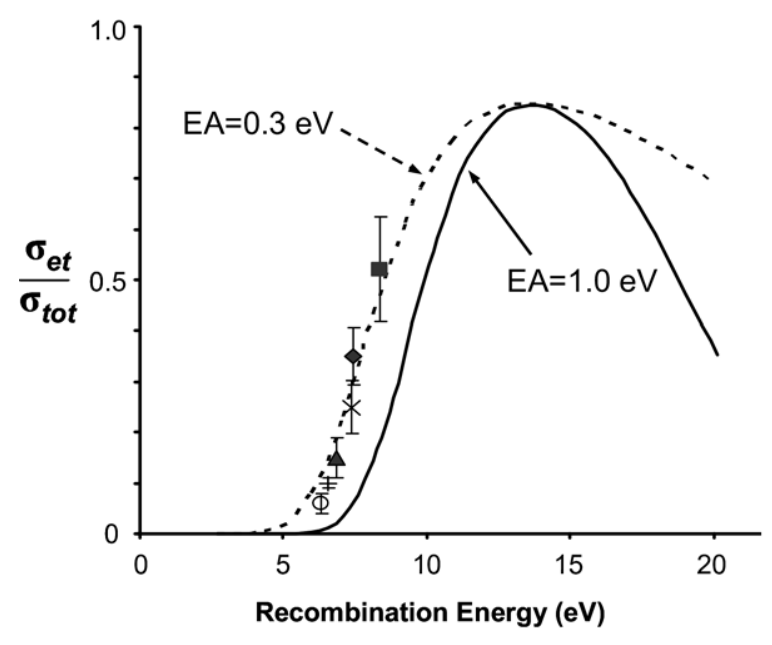

Figure 6. Effect of changing the electron affinity (EA) on the contribution of electron-transfer as a function of recombination energy (RE) for the $\left(\mathrm{A}_{6}-4 \mathrm{H}\right)^{4-}$ anion. The dashed line represents $\mathrm{EA}=0.3 \mathrm{eV}$, and the solid line represents $\mathrm{EA}=1.0 \mathrm{eV}$. The symbols indicate the measured fraction of electron-transfer product for each metal complex $\left[\mathrm{Cu}^{\mathrm{II}}(\text { phen })_{2}\right]^{2+}$ (filled square), $\left[\mathrm{Co}^{\mathrm{II}}(\text { phen })_{2}\right]^{2+}$ (filled diamond), $\left[\mathrm{Fe}^{\mathrm{II}}(\text { phen })_{2}\right]^{2+}$ (multiplication symbol), $\left[\mathrm{Cu}^{\mathrm{II}}(\text { phen })_{3}\right]^{2+}$ (filled triangle), $\left[\mathrm{CO}(\text { phen })_{3}\right]^{2+}$ (plus symbol), $\left[\mathrm{Fe}^{\mathrm{II}}(\text { phen })_{3}\right]^{2+}$ (open circle).

electron-transfer between reactant and product electronic ground states. Therefore, reactants with RE values higher than $9.5 \mathrm{eV}$ may show significant electrontransfer if an excited electronic state of a product is formed. Hence, it is not clear that a cation RE can be too high for efficient electron-transfer but it can be too low. The calculated RE values for the divalent transition-

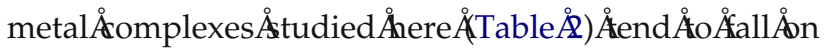
the side where the slope of the $\sigma_{\text {et }} / \sigma_{\text {tot }}$ versus RE curve is positive. The $\mathrm{Cu}$ (II) complexes have the highest $\mathrm{RE}$ values and show the most electron-transfer compared with the $\mathrm{Co}$ (II) or $\mathrm{Fe}(\mathrm{II})$ analogs. The tris-phen complexes have lower RE values than the corresponding bis-phen complexes and also show significantly lower contributions from electron-transfer, which is consistent with the plot $\begin{gathered}\text { f } \\ \text { Figure }\end{gathered}$

The hexa-dA charge state affects the prediction made by this model in several ways. As absolute charge state increases, the anion EA value becomes less positive. For a constant cation RE value, this increases reaction exothermicity. For the RE values associated with the cations in this work, the model predicts an increase in $\sigma_{\text {et }} / \sigma_{\text {tot }}$ as the EA decreases (over the range that the $\mathrm{H}_{12}$ relationship was initially established). Hence, an increase in electron-transfer would be expected as the absolute anion charge state increases. However, the anion charge state also affects the terms in the denominator in the exponential term of relation 6 . It affects both the difference in the slopes of the product and reactant channels as well as the radial velocity at the crossing point. The effect of the change in EA and the effect of the charge state change are competing, as

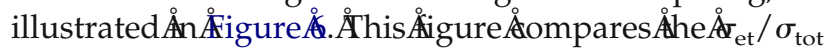

dependence on RE using relation 10 for $b_{\text {et }}[2] \AA$ for the $\left(\mathrm{A}_{6}-4 \mathrm{H}\right)^{4-}$ anion and varying the EA of the anion. The calculation used the same parameters described for

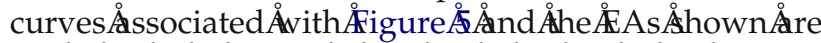
EA $\AA \AA$ A. 0 Ås Ån of a change in EA, the increase in the absolute charge of the anion shifts the highest electron-transfer probability to higher RE values. A reduction in the EA value of the anion, however, tends to shift the maximum back to a lower RE value. For an increase in electron-transfer to be observed as the absolute charge of the anion increases, the anion EA must decrease sufficiently to overcome the effect of the changes in the difference of the reactant and product slopes and radial velocity. These competing effects may account for the fact that the $\left(\mathrm{A}_{6}-4 \mathrm{H}\right)^{4-}$ anion shows less electron-transfer than either the $\left(\mathrm{A}_{6}-3 \mathrm{H}\right)^{3-}$ or $\left(\mathrm{A}_{6}-5 \mathrm{H}\right)^{5-}$ charge states with the $\left[\mathrm{M}^{\mathrm{II}}(\text { phen })_{2}\right]^{2+}$ anions.

\section{Considerations for Ion Transformation}

The ion/ion reactions of the divalent transition-metal complexes studied here can transform deprotonated ODNs to charge reduced ODNs via electron-transfer (Scheme 1, reaction 1, or to ODNs with divalent transitionmetal counter-ions (via reaction 2), or to adduct species (e.g., via reaction 3). From an ion transformation standpoint, transition-metal complexes do not appear to offer particular advantages over other reagent ions for electron-transfer. Previous ion/ion reaction studies with ODN anions have demonstrated reagent species that can affect electron-transfer without complications from adduct formation. It is the ability to insert multivalent transition-metal ions into ODN anions that is unique to the work presented here. The extent to which divalent metal insertion competes with charge-transfer is affected by such variables as the RE of the di-cation, the coordination sphere of the metal, the nature of the ligand, and the charge state and EA of the ODN. For the species studied here, it is apparent that divalent metal ion insertion to yield a single product ion type (via reaction 2) can be maximized by use of tris-phenanthroline complexes. The use of the tris-phenanthroline complexes minimizes the RE of the cation and thereby minimizes electron-transfer.

\section{Conclusions}

Cationic complexes of multivalent transition-metal complexes react with multiply charged hexa-dA anions via two major competing pathways. These include electron-transfer from the hexa-dA anion to the cation and condensation of the anionic and cationic reactants to form a long-lived complex. Depending upon the metal and ligand, hexa-dA displacement of the ligands can be a facile process that results in the incorporation of the multivalent metal into the hexa-dA anion. For a given hexa-dA anion, electron-transfer to the cation appears to correlate with the recombination energy of the 
transition-metal complex cation. The tris-phenanthroline complexes have lower recombination energies than their bis-phenanthroline counterparts and therefore generally show less electron-transfer. The unique reaction channels demonstrated by the transition-metal complexes are those that lead to incorporation of the transition-metal into the ODN.

In some cases, the adduct formation product resulting from the combination of the two oppositely charged ions is observed. The tendency for this to occur appears to correlate with the facility with which ligand substitution is known to take place in solution. Overall, the experiments described here indicate that the partitioning of ion/ion reaction products can be significantly affected by judicious selection of the coordination environment of the metal and that metal complexes of this sort can be used as reagents for inserting multivalent transition metals into oligodeoxynucleotides.

\section{Acknowledgments}

CKB gratefully acknowledges an Australian postgraduate award and University of Melbourne PORES scholarship. RAJO acknowledges the Faculty of Science, University of Melbourne for special studies program leave and financial support. CKB and RAJO thank the ARC for financial support of this work under the ARC Centres of Excellence program (ARC Centre of Excellence in Free Radical Chemistry and Biotechnology). The authors gratefully acknowledge the generous allocation of computing time from the Victorian Institute for Chemical Science High Performance Computing Facility, and Sioe See Volaric for donation of the ruthenium(II) compounds. BDMH, YX, and SAM acknowledge support from the Office of Basic Energy Sciences, Division of Chemical Sciences under award no. DE-FG02-00ER15105. Special thanks go to W. David McFadyen for helpful discussions in the preparation of this manuscript.

\section{References}

1. Christian, N. P.; Colby, S. M.; Giver, L.; Houston, C. T.; Arnold, R. J.; Ellington, A. D.; Reilly, J. P. High-Resolution Matrix-Assisted LaserDesorption Ionization Time-of-Flight Analysis of Single-Stranded-DNA of 27 to 68 Nucleotides in Length. Rapid Commun. Mass Spectrom. 1995, 9, 1061-1066.

2. Christian, N. P.; Giver, L.; Ellington, A. D.; Reilly, J. P. Effects of Matrix Variations and the Presence of Iron on Matrix-Assisted Laser Desorption/Ionization Mass Spectra of DNA. Rapid Commun. Mass Spectrom. 1996, 10, 1980-1986.

3. Hettich, R. L.; Stemmler, E. A. Investigation of Oligonucleotide Fragmentation With Matrix-Assisted Laser Desorption Ionization FourierTransform Mass Spectrometry and Sustained Off-Resonance Irradiation. Rapid Commun. Mass Spectrom. 1996, 10, 321-327.

4. Hettich, R. L. Formation and Characterization of Iron-Oligonucleotide Complexes with Matrix-Assisted Laser Desorption/Ionization Fourier Transform Ion Cyclotron Resonance Mass Spectrometry. J. Am. Soc. Mass Spectrom. 1999, 10, 941-949.

5. Hettich, R. L. Investigating the Effect of Transition Metal Ion Oxidation State on Oligodeoxyribonucleotide Binding By Matrix-Assisted Laser Desorption/Ionization Fourier Transform Ion Cyclotron Resonance Mass Spectrometry. Int. J. Mass Spectrom. 2001, 204, 55-75.

6. Wang, Y.; Taylor, J.-S.; Gross, M. L. Fragmentation of ElectrosprayProduced Oligodeoxynucleotide Ions Adducted to Metal Ions. J. Am. Soc. Mass Spectrom. 2001, 12, 550-556.

7. Keller, K. M.; Brodbelt, J. S. Charge State-Dependent Fragmentation of Oligonucleotide/Metal Complexes. J. Am. Soc. Mass Spectrom. 2005, 16, 28-37.

8. Monn, S. T. M.; Schürch, S. Investigation of Metal-Oligonucleotide Complexes by Nanoelectrospray Tandem Mass Spectrometry in the Positive Mode. J. Am. Soc. Mass Spectrom. 2005, 16, 370-378.

9. Wu, J.; McLuckey, S. A. Gas-Phase Fragmentation of Oligonucleotide Ions. Int. J. Mass Spectrom. 2004, 237, 197-241.
10. Hertzberg, R. P.; Dervan, P. B. Cleavage of Double Helical DNA by Methidium-Propyl-EDTA-Iron(II). J. Am. Chem. Soc. 1982, 104, 313-315.

11. Barton, J. K. Metals and DNA: Molecular Left-Handed Complements. Science 1986, 233, 727-734.

12. Erkkila, K. E.; Odom, D. T.; Barton, J. K. Recognition and Reaction of Metallointercalators with DNA. Chem. Rev. 1999, 99, 2777-2796.

13. Sherman, S. E.; Gibson, D.; Wang, A. H.-J.; Lippard, S. J. X-Ray Structure of the Major Adduct of the Anticancer Drug Cisplatin with DNA: Cis-[Pt $\left.\left(\mathrm{NH}_{3}\right)_{2}\{\mathrm{~d}(\mathrm{pGpG})\}\right]$. Science 1985, 230, 412-417.

14. Takahara, P. M.; Rosenzweig, A. C.; Frederick, C. A.; Lippard, S. J. Crystal Structure of Double Stranded DNA Containing the Major Adduct of the Anticancer Drug Cisplatin. Nature 1995, 377, 649-652.

15. Dyson, P. J.; Sava, G. Metal-based Antitumor Drugs in the PostGenomic Era. Dalton Trans. 2006, 2006, 1929-1933.

16. Beck, J. L.; Colgrave, M. L.; Ralph, S. F.; Sheil, M. M. Electrospray Ionization Mass Spectrometry of Oligonucleotide Complexes with Drugs, Metals, and Proteins. Mass Spectrom. Rev. 2001, 20, 61-87.

17. Pitteri, S. J.; McLuckey, S. A. Recent Developments in the Ion/Ion Chemistry of High-Mass Multiply Charged Ions. Mass Spectrom. Rev. 2005, 24, 931-958.

18. Stephenson, J. L., Jr.; McLuckey, S. A. Ion/Ion Reactions in the Gas Phase: Proton Transfer Reactions Involving Multiply-Charged Proteins. J. Am. Chem. Soc. 1996, 118, 7390-7397.

19. Wells, J. M.; Chrisman, P. A.; McLuckey, S. A. Formation and Characterization of Protein-Protein Complexes in Vacuo. J. Am. Chem. Soc. 2003, 125, 7238-7249.

20. Gunawardena, H. P.; He, M.; Chrisman, P. A.; Pitteri, S. J.; Hogan, J. M.; Hodges, B. D. M.; McLuckey, S. A. Electron Transfer versus Proton Transfer in Gas-Phase Ion/Ion Reactions of Polyprotonated Peptides. I. Am. Chem. Soc. 2005, 127, 12627-12639.

21. Newton, K. A.; McLuckey, S. A. Gas-Phase Peptide/Protein Cationizing Agent Switching via Ion/Ion Reactions. J. Am. Chem. Soc. 2003, 125 , 12404-12405.

22. Newton, K. A.; Amunugama, R.; McLuckey, S. A. Gas-Phase Ion/Ion Reactions of Multiply Protonated Polypeptides with Metal Containing Anions. J. Phys. Chem. A 2005, 109, 3608-3616.

23. Gunawardena, H. P.; O'Hair, R. A. J.; McLuckey, S. A. Selective Disulfide Bond Cleavage in Gold(I) Cationized Polypeptide Ions Formed via Gas-Phase Ion/Ion Cation Switching. J. Proteome Res. 2006, 5, 2087-2092.

24. Hodges, B. D. M.; Liang, X.; McLuckey, S. A. Generation of Di-lithiated Peptide Ions from Multiply Protonated Peptides via Ion/Ion Reactions. Int. J. Mass Spectrom. 2007, 267, 183-189.

25. Katta, V.; Chowdhury, S. K.; Chait, B. T. Electrospray Ionization: A New Tool for the Analysis of Ionic Transition-Metal Complexes. J. Am. Chem. Soc. 1990, 112, 5348-5349.

26. Colton, R.; D'Agopstino, A.; Traeger, J. C. Electrospray Mass Spectrometry Applied to Inorganic and Organometallic Chemistry. Mass Spectrom. Rev. 1995, 14, 79-106.

27. Gatlin, C. L.; Turecek, F. In Electrospray Ionization Mass Spectrometry, Fundamentals, Instrumentation and Applications; Cole, R. B., Ed. Wiley: New York, 1997; Chap. XV, pp 527-570.

28. Fisher, K. J. Gas-Phase Coordination Chemistry of Transition Metal Ions. Prog. Inorg. Chem. 2001, 50, 343-432.

29. Satterfield, M.; Brodbelt, J. S. Relative Binding Energies of Gas-Phase Pyridyl Ligand/Metal Complexes by Energy-Variable Collisionally Activated Dissociation in a Quadrupole Ion Trap. Inorg. Chem. 2001, 400, 5393-5400.

30. Alvarez, E. J.; Vartanian, V. H.; Brodbelt, J. S. Dissociation of Polyether Transition Metal Ion Dimer Complexes in a Quadrupole Ion Trap. J. Am. Soc. Mass Spectrom. 1997, 8, 620-629.

31. Gatlin, C. L.; Turecek, F.; Vaisar, T. J. Copper(II) Amino-Acid Complexes in the Gas Phase. J. Am. Chem. Soc. 1995, 117, 3637-3638.

32. Chaparro, A. L.; Vachet, R. W. Tandem Mass Spectrometry of Cu(II) Complexes: The Effects of Ligand Donor Group on Dissociation. J. Mass Spectrom. 2003, 38, 333-342.

33. Anichina, J.; Zhao, X.; Bohme, D. K. Metal and Ligation-Dependent Fragmentation of $\left[\mathrm{M}(1,10 \text {-Phenanthroline })_{1,2,3}\right]^{2+}$ Cations with $\mathrm{M}=$ $\mathrm{Mn}, \mathrm{Fe}, \mathrm{Co}, \mathrm{Ni}, \mathrm{Cu}$, and $\mathrm{Zn}$ : Comparison Between the Gas Phase and Solution. J. Phys. Chem. A 2006, 110, 10763-10769.

34. Combariza, M. Y.; Vachet, R. W. Effect of Coordination Geometry on the Gas-Phase Reactivity of Four-Coordinate Divalent Metal Ion Complexes. J. Phys. Chem. A 2004, 108, 1757-1763.

35. Combariza, M. Y.; Vachet, R. W. Gas-Phase Ion-Molecule Reactions of Transition Metal Complexes: The Effect of Different Coordination Spheres on Complex Reactivity. J. Am. Soc. Mass Spectrom. 2002, 13, $813-825$.

36. Combariza, M. Y.; Vachet, R. W. The Utility of Ion-Molecule Reactions in a Quadrupole Ion Trap Mass Spectrometer for Analyzing Metal Complex Coordination Structure. Anal. Chim. Acta 496, 2003, 233-248

37. Armentrout, P. B.; Beauchamp, J. L. The Chemistry of Atomic Transition Metal Ions: Insight into Fundamental Aspects of Organometallic Chemistry. Acc. Chem. Res. 1989, 22, 315-321.

38. Freiser, B. S., Ed. Organometallic Ion Chemistry. Understanding Chemical Reactivity, XV; Kluwer Academic: Dordrecht, 1966.

39. Eller, K.; Schwarz, H. Organometallic Chemistry in the Gas Phase. Chem. Rev. 1991, 91, 1121-1177.

40. Freiser, B. S. Selected Topics in Organometallic Ion Chemistry. Acc. Chem. Res. 1994, 27, 353-360. 
41. Armentrout, P. B. Building Organometallic Complexes from the Bare Metal: Thermochemistry and Electronic Structure Along the Way. Acc. Chem. Res. 1995, 28, 430-436.

42. Rodgers, M. T.; Armentrout, P. B. Noncovalent Metal-Ligand Bond Energies as Studied by Threshold Collision-Induced Dissociation. Mass Spectrom. Rev. 2000, 19, 215-247.

43. O'Hair, R. A. J. The 3D Quadrupole Ion Trap Mass Spectrometer as a Complete Chemical Laboratory for Fundamental Gas-Phase Studies of Metal Mediated Chemistry. Chem. Commun. 2006, 2006, 1469-1481.

44. Xia, Y.; Liang, X.; McLuckey, S. A. Pulsed Dual Electrospray Ionization for Ion/Ion Reactions. J. Am. Soc. Mass Spectrom. 2005, 16, 1750-1756.

45. Xia, Y.; Chrisman, P. A.; Erickson, D. E.; Liu, J.; Liang, X.; Londry, F. A.; Yang, M. J.; McLuckey, S. A. Implementation of Ion/Ion Reactions in a Quadrupole/Time-of-Flight Tandem Mass Spectrometer. Anal. Chem. 2006, 78, 4146-4154

46. Barlow, C. K.; McFadyen, W. D.; O'Hair, R. A. J. Formation of Cationic Peptide Radicals by Gas-Phase Redox Reactions with Trivalent Chromium, Manganese, Iron, and Cobalt Complexes. J. Am. Chem. Soc. 2005, 127, 6109-6115.

47. Frisch, M. J.; Trucks, G. W.; Schlegel, H. B.; Scuseria, G. E.; Robb, M. A.; Cheeseman, J. R.; Montgomery, Jr., J. A.; Vreven, T.; Kudin, K. N.; Burant, J. C.; Millam, J. M.; Iyengar, S. S.; Tomasi, J.; Barone, V. Mennucci, B.; Cossi, M.; Scalmani, G.; Rega, N.; Petersson, G. A.; Nakatsuji, H.; Hada, M.; Ehara, M.; Toyota, K.; Fukuda, R.; Hasegawa, J.; Ishida, M.; Nakajima, T.; Honda, Y.; Kitao, O.; Nakai, H.; Klene, M.; Li, X.; Knox, J. E.; Hratchian, H. P.; Cross, J. B.; Bakken, V.; Adamo, C. Jaramillo, J.; Gomperts, R.; Stratmann, R. E.; Yazyev, O.; Austin, A. J.; Cammi, R.; Pomelli, C.; Ochterski, J. W.; Ayala, P. Y.; Morokuma, K.; Voth, G. A.; Salvador, P.; Dannenberg, J. J.; Zakrzewski, V. G.; Dapprich, S.; Daniels, A. D.; Strain, M. C.; Farkas, O.; Malick, D. K.; Rabuck, A. D.; Raghavachari, K.; Foresman, J. B.; Ortiz, J. V.; Cui, Q.; Baboul, A. G.; Clifford, S.; Cioslowski, J.: Stefanov, B. B.; Liu, G.; Liashenko, A. Piskorz, P.; Komaromi, I.; Martin, R. L.; Fox, D. J.; Keith, T.; Al-Laham, M. A.; Peng, C. Y.; Nanayakkara, A.; Challacombe, M.; Gill, P. M. W.; Johnson, B.; Chen, W.; Wong, M. W.; Gonzalez, C.; Pople, J. A. Gaussian 03 2004; Gaussian, Inc.: Wallingford, CT.

48. McLuckey, S. A.; Stephenson, J. L., Jr.; O'Hair, R. A. J. Decompositions of Odd- and Even-Electron Anions Derived From Deoxy-Polyadenylates. J. Am. Soc. Mass Spectrom. 1997, 8, 148-154.

49. Herron, W. J.; Goeringer, D. E.; McLuckey, S. A. Gas-Phase Electron Transfer Reactions from Multiply-Charged Anions to Rare Gas Cations. J. Am. Chem. Soc. 1995, 117, 11555-11562.

50. Stephenson, J. L., Jr.; McLuckey, S. A. Charge Reduction of Oligonucleotide Anions via Gas Phase Electron Transfer to Xenon Cations. Rapid Commun. Mass Spectrom. 1997, 11, 875-880.

51. Wu, J.; McLuckey, S. A. Ion/Ion Reactions of Multiply Charged Nucleic Acid Anions: Electron Transfer, Proton Transfer, and Ion Attachment. Int. J. Mass Spectrom. 2003, 228, 577-597.

52. McLuckey, S. A.; Wu, J.; Bundy, J. L.; Stephenson, J. L., Jr.; Hurst, G. B. Oligonucleotide Mixture Analysis via Electrospray and Ion/Ion Reactions in a Quadrupole Ion Trap. Anal. Chem. 2002, 74, 976-984.

53. Xia, Y.; Chrisman, P. A.; Pitteri, S. J.; Erickson, D. E.; McLuckey, S. A Ion/Molecule Reactions of Cation Radicals Formed from Protonated
Polypeptides via Gas-Phase Ion/Ion Electron Transfer. J. Am. Chem. Soc. 2006, 128, 11792-11798.

54. McLuckey, S. A.; Van Berkel, G. J.; Glish, G. L. Tandem Mass Spectrometry of Small, Multiply Charged Oligonucleotides. J. Am. Soc. Mass Spectrom. 1992, 3, 60-70.

55. Brandt, W. W.; Dwyer, F. P.; Gyarfas, E. D. Chelate Complexes of 1,10-Phenanthroline and Related Compounds. Chem. Rev. 1954, 54, 959-1017.

56. Klassen, J. S.; Schnier, P. D.; Williams, E. R. Blackbody Infrared Radiative Dissociation of Oligonucleotide Anions. J. Am. Soc. Mass Spectrom. 1998, 9, 1117-1124.

57. Cotton, F. A.; Wilkinson, G.; Murillo, C. A.; Bochmann, M. In Advanced Inorganic Chemistry; John Wiley and Sons: New York, 1999; pp 2-824.

58. Mahan, B. H. Recombination of Gaseous Ions. In Advances in Chemical Physics; Prigogine, I., Ed. Wiley: New York, 1973; pp 1-40.

59. Zener, C. Nonadiabatic Crossing of Energy Levels. Proc. Royal Soc London. 1932, A136, 696-702.

60. Landau, L. D. On the Theory of Transfer of Energy at Collisions. II. Phys. Z (USSR) 1932, 2, 46-51

61. Olson, R. E.; Smith, F. T.; Bauer, E. Estimation of the Coupling Matrix Elements for One-Electron Transfer Systems. Appl. Optics 1971, 10, 1848-1855.

62. Olson, R. E. Absorbing-Sphere Model for Calculating Ion-Ion Recombination Total Cross Sections. J. Chem. Phys. 1972, 56, 2979-2984.

63. Lindoy, L. F.; Livingstone, S. E. Complexes of Iron(II), Cobalt(II), and Nickel(II) With $\alpha$-Di-imines and Related Bidentate Ligands. Coord. Chem. Rev. 1967, 2, 173-193.

64. Köenig, E. Chemistry of Bis(2,2'-Dipyridyl) and Bis(1,10-Phenanthroline) Complexes of Iron(II). Coord. Chem. Rev. 1968, 3, 471-495.

65. Wang, L. S.; Ding, C. F.; Wang, X. B.; Nicholas, J. B.; Nicholas, B. Probing the Potential Barriers and Intramolecular Electrostatic Interactions in Free Doubly Charged Anions. Phys. Rev. Lett. 1998, 81, 2667-2670.

66. Weber, J. M.; Ioffe, I. N.; Berndt, K. M.; Löffler, D.; Friedrich, J.; Ehrler, O. T.; Danell, A. S.; Parks, J. H.; Kappes, M. M. Photoelectron Spectroscopy of Isolated Multiply Negatively Charged Oligonucleotides. J. Am. Chem. Soc. 2004, 126, 8585-8589.

67. Gronert, S. Estimation of Effective Ion Temperatures in a Quadrupole Ion Trap. J. Am. Soc. Mass Spectrom. 1998, 8, 845-848.

68. Asano, K. G.; Goeringer, D. E.; McLuckey, S. A. Thermal Dissociation in the Quadrupole Ion Trap: Ions Derived from Leucine Enkephalin. Int. J. Mass Spectrom. 1999, 185/186/187, 207-219.

69. Asano, K. G.; Butcher, D. J.; Goeringer, D. E.; McLuckey, S. A. Effective Ion Internal Temperature Achieved via Boundary Activation in the Quadrupole Ion Trap: Protonated Leucine Enkephalin. J. Mass Spectrom. 1999, 34, 691-698.

70. Butcher, D. J.; Asano, K. G.; Goeringer, D. E.; McLuckey, S. A. Thermal Dissociation of Gaseous Bradykinin Ions. J. Phys. Chem. A 1999, 103, $8664-8671$.

71. Goeringer, D. E.; Asano, K. G.; McLuckey, S.A. Ion Internal Temperature and Ion Trap Collisional Activation: Protonated Leucine Enkephalin. Int. J. Mass Spectrom. 1999, 182/183, 275-288. 